\title{
Double lung transplantation in situs inversus with Kartagener's syndrome
}

En bloc double lung transplantation with bilateral bronchial anastomoses was successfully performed in three patients with complete situs inversus and end-stage Kartagener's syndrome. Dextrocardia was not a technical problem for institution of cardiopulmonary bypass, but a large azygos vein draining the systemic venous return was systematically preserved. The major technical difficulty was restoration of airway continuity, because patients with situs inversus have an inverse direction and length of the main stem bronchi. The right and left main bronchi of the recipients were approached in the aortocaval sinus and transected approximately at $1.5 \mathrm{~cm}$ from the carina. The donor right main stem bronchus was divided at its origin and the donor left main stem bronchus was divided proximal to the upper lobe takeoff. The different bronchial angulation was not an obstacle, and airway continuity was reestablished twice with an end-to-end anastomosis and once with a telescopic technique. Because of the midline position of the left atrium and pulmonary artery, the anastomoses with the respective recipient's structures were made as in patients with situs solitus. One patient required a right lower lobectomy because the position of the right side of the heart interfered with lobar expansion. One patient died of obliterative bronchiolitis 36 months after the operation. The remaining two are alive and doing well after 48 and 6 months, respectively. (J THORAC CaRdiovaSC SuRg 1994;108:86-91)

Paolo Macchiarini, MD, ${ }^{\text {a }}$ Alain Chapelier, MD, ${ }^{\text {a }}$ Pascal Vouhé, MD, Jacques Cerrina, MD, ${ }^{\mathrm{a}}$

François Le Roy Ladurie, MD, ${ }^{\mathrm{a}}$ François Parquin, MD, ${ }^{\mathrm{a}}$ François Brenot, MD, ${ }^{\mathrm{b}}$

Gérald Simonneau, MD, ${ }^{\mathrm{b}}$ and Philippe Dartevelle, MD, ${ }^{\mathrm{a}}$ for the Paris-Sud University Lung

Transplant Group, ${ }^{*}$ Le Plessis Robinson and Clamart, France

K artagener's syndrome, a congenital disease transmitted as an autosomal recessive illness with a prevalence

From the Departments of Thoracic and Vascular Surgery and Heart-

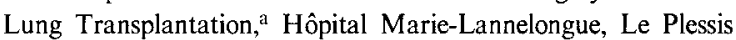
Robinson, and Pneumology, ${ }^{\mathrm{b}}$ Hôpital Beclère, Clamart, Paris-Sud University, Paris, France.

Received for publication Nov. 19, 1993.

Accepted for publication Feb. 22, 1994.

Address for reprints: Paolo Macchiarini, MD, Department of Thoracic and Vascular Surgery and Heart-Lung Transplantation, Hôpital Marie-Lannelongue (Paris-Sud University), 133, Avenue de la Resistance, 92350 Plessis Robinson, France.

*For a listing of the Paris-Sud University Lung Transplant Group, see end of article.

Copyright 1994 by Mosby-Year Book, Inc.

$0022-5223 / 94 \$ 3.00+0 \quad \mathbf{1 2} / \mathbf{1} / \mathbf{5 5 3 9 2}$ of approximately 1:20,000 persons, is characterized by the triple association of situs inversus, bronchiectasis, and sinusitis. ${ }^{1}$ Affected patients have an incoordination of ciliary motility that leads to defective mucociliary transport, chronic bronchial infections, and ultimately end-stage respiratory failure. ${ }^{2}$ Medical treatment usually has a palliative goal as does surgery, which has rarely been performed and has been confined to resection of the pathologic pulmonary segments. ${ }^{3}$

Combined heart-lung transplantation has recently been introduced ${ }^{4}$ as an effective treatment modality for a variety of heart and lung diseases. ${ }^{5}$ Unfortunately, this procedure is limited for patients with Kartagener's syndrome because the probability of finding a suitable donor with situs inversus is extremely low and the absence of a situs solitus imposes major technical difficulties. Interest- 
ingly, Miralles and associates ${ }^{6}$ have recently demonstrated that such technical drawbacks might be overcome by creating a large single atrium with the residual recipient right and left atria that can be subsequently anastomosed with the donor's right atrium. This procedure is, however, a technical challenge. Its major disadvantages include the unnecessary heart transplantation and the risks of early and long-term complications of the donor heart, such as cardiac rejection and accelerated graft atherosclerosis.

Double lung transplantation (DLT) offers the potential advantages of preserving the native heart, thereby optimizing this organ's use, and allowing a longer lung ischemic time. ${ }^{7}$ Although DLT has become the treatment of choice for generalized bronchiectasis, ${ }^{5}$ it has never been performed in patients with situs inversus and Kartagener's syndrome. We present a modification of the technique of en bloc DLT described by Patterson and associates ${ }^{7}$ that was successfully applied in three patients with this disease.

\section{Patients and methods}

Since the beginning of our lung transplant program in 1986 , 105 patients have undergone heart-lung $(n=59)$, single lung ( $n=10)$, and double lung $(n=36)$ transplantation for primary pulmonary hypertension $(n=38)$, chronic respiratory failure $(n=46)$, Eisenmenger's syndrome $(n=15)$, and chronic pulmonary embolism $(n=6)$. Among the 36 patients undergoing DLT, three had Kartagener's syndrome and situs inversus and are the subject of this article.

CASE 1. A 41-year-old woman was referred to us in December 1988 with end-stage Kartagener's syndrome including complete situs inversus, generalized bronchiectasis, and sinusitis. She was bedridden, having had marked dyspnea at rest since 1985 and having become fully disabled, requiring oxygen therapy, in 1986. Meanwhile, recurrent episodes of hemoptysis, chronic respiratory infections, and right-sided heart failure were observed. After referral, a tracheostomy and mechanical ventilation were required for severe alveolar hypoventilation lasting 3 months. In July 1989, during a pretransplantation workup she again required a tracheostomy and mechanical ventilation (arterial oxygen tension of $30 \mathrm{~mm} \mathrm{Hg}$ and arterial carbon dioxide tension of $50 \mathrm{~mm} \mathrm{Hg}$ ); marked right-sided heart failure necessitated inotropic assistance (dobutamine, $15 \mathrm{\gamma} / \mathrm{kg}$ per minute). She had a bacterial colonization of the tracheobronchial tract with strains of Pseudomonas aeruginosa and Acinetobacter calcoaceticus, managed with antibiotic therapy. Her preoperative profile is depicted in Table I. She underwent transplantation in September 1989.

CASE 2. A 38-year-old man was referred in December 1990 with end-stage Kartagener's syndrome with generalized bronchiectasis, complete situs inversus, bilateral sinusitis, and a 2-year history of dyspnea at rest, respiratory insufficiency (arterial oxygen tension of $45 \mathrm{~mm} \mathrm{Hg}$, arterial carbon dioxide tension of $50 \mathrm{~mm} \mathrm{Hg}$ ) treated with physiotherapy and oxygen therapy, and clinical signs of right-sided heart failure. He had a bronchial bacterial colonization with strains of $P$. aeruginosa,
Table I. Preoperative respiratory, hemodynamic, serologic and structural profile

\begin{tabular}{|c|c|c|c|}
\hline & Patient 1 & Patient 2 & Patient 3 \\
\hline \multicolumn{4}{|l|}{ Respiratory function } \\
\hline $\mathrm{FEV}_{\mathrm{l}}, \mathrm{L}(\%$ predicted value) & - $^{*}$ & $0.8(21 \%)$ & $0.7(24 \%)$ \\
\hline VC, L (\% predicted value) & -* & $1.7(37 \%)$ & $1.4(33 \%)$ \\
\hline $\mathrm{FEV}_{1} / \mathrm{VC}$ (\% predicted value) & - $^{*}$ & $48 \%$ & $50 \%$ \\
\hline \multicolumn{4}{|l|}{ Hemodynamic } \\
\hline $\mathrm{RAP}(\mathrm{mm} \mathrm{Hg})$ & 4 & 10 & 4 \\
\hline PAP $(\mathrm{mm} \mathrm{Hg})$ & 27 & 44 & 49 \\
\hline PCWP $(\mathrm{mm} \mathrm{Hg})$ & 10 & 10 & 12 \\
\hline $\mathrm{CI}\left(\mathrm{L} \cdot \mathrm{min}^{-2} \cdot \mathrm{m}^{-1}\right)$ & 4.9 & 4 & 3.9 \\
\hline NYHA class & IV & IV & IV \\
\hline ABO blood group & A+ & $\mathrm{O}+$ & $\mathrm{O}+$ \\
\hline \multirow[t]{6}{*}{ HLA antigens } & $\mathrm{A}_{2}$ & $\mathrm{~A}_{24}$ & $\mathrm{~A}_{2}$ \\
\hline & $\mathrm{A}_{32}$ & $\mathrm{~A}_{30}$ & $\mathrm{~A}_{29}$ \\
\hline & $\mathrm{B}_{12}$ & $\mathrm{~B}_{44}$ & $\mathrm{~B}_{12}$ \\
\hline & $\mathrm{B}_{27}$ & $\mathrm{~B}_{3 i}$ & $\mathrm{~B}_{16}$ \\
\hline & $\mathrm{DR}_{2}$ & $\mathrm{DR}_{7}$ & $\mathrm{DR}_{11}$ \\
\hline & $\mathrm{DR}_{5}$ & $\mathrm{DR}_{13}$ & $\mathrm{DR}_{7}$ \\
\hline Cytomegalovirus & Positive & Positive & Negative \\
\hline Human immunodeficiency virus & Negative & Negative & Negative \\
\hline Hepatitis B serology & Negative & Negative & Negative \\
\hline Toxoplasmosis & Positive & Positive & Negative \\
\hline Height $(\mathrm{cm})$ & 155 & 175 & 167 \\
\hline Weight (kg) & 40 & 55 & 62 \\
\hline Thoracic perimeter $(\mathrm{cm})$ & 71 & 85 & 91 \\
\hline
\end{tabular}

$F E V_{l}$, Forced expiratory volume in the first second; $V C$, vital capacity; $R A P$, right atrial pressure; $P A P$, pulmonary artery pressure (mean); $P C W P$, pulmonary capillary wedge pressure; $C I$, cardiac index.

sterilized with antibiotic therapy. His pretransplantation profile is depicted in Table I. After being considered for DLT since January 1991, he was operated on in March 1991.

CASE 3. A 49-year-old man was referred in June 1992 with end-stage Kartagener's syndrome including septic bronchiectasis, complete situs inversus, and bilateral sinusitis and otitis. $\mathrm{He}$ had been bedridden with severe dyspnea at rest requiring oxygen therapy since February 1992. His arterial blood gas analysis showed an arterial oxygen tension of $79 \mathrm{~mm} \mathrm{Hg}$ and an arterial carbon dioxide tension of $57 \mathrm{~mm} \mathrm{Hg}$ with $4 \mathrm{~L}$ of oxygen therapy by nasal prongs. He had a bacterial colonization of the bronchial tract with strains of $P$. aeruginos $a$, managed with antibiotic therapy. After pretransplantation assessment (Table I), he was put on the waiting list in July 1992 and underwent transplantation in August 1993.

Operations. Donor organs were harvested according to the technique described by the Washington University group. ${ }^{8}$ The lungs were preserved by administration of prostacyclin via the main pulmonary artery immediately before pulmonary artery flush with modified Papworth solution.?

In the recipients, the operation was performed through a median sternotomy in two patients and through a transverse bilateral thoracosternotomy in the last one. All three patients had complete situs inversus with dextrocardia. The pulmonary artery was anterior to the aorta and originated from the left ventricle. The aorta originated from the right ventricle and its arch and thoracic tract were on the right side (Fig. 1). The inferior vena cava was left-sided and drained only the suprahepatic veins, whereas a left-sided superior vena cava drained the 


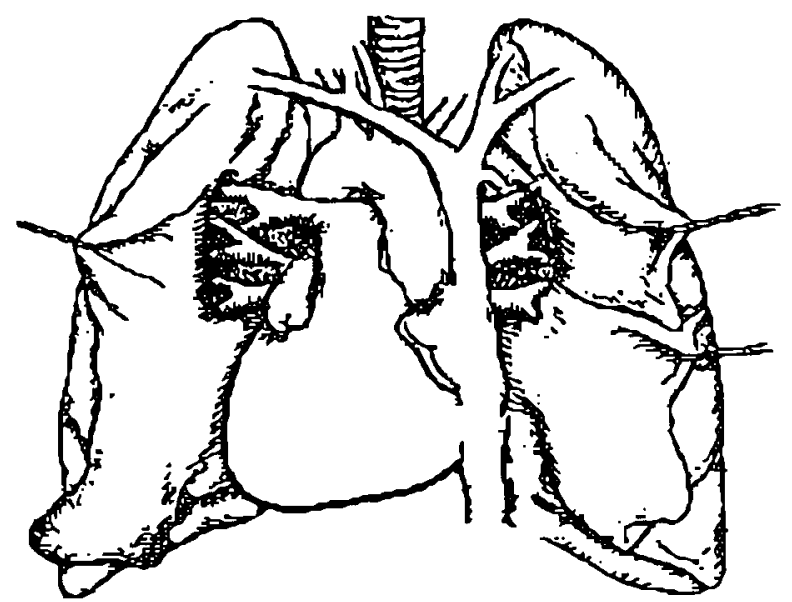

Fig. 1. Thoracic anatomy of situs inversus. The heart is rightsided. The pulmonary artery is anterior to the aorta and originates from the left ventricle. The aorta originates from the right ventricle and its arch and thoracic tract are on the right. The superior and inferior venae cavae are left-sided.

remaining inferior and superior venous return by an enormous azygos vein. Both lungs were also in an inverse position because the right and left lungs had two and three lobes, respectively.

DLT included a modification of the technique described by Patterson and associates. ${ }^{7}$ All patients had pleuroparietal adherences that were freed before normothermic cardiopulmonary bypass was instituted after ascending aorta and atriocaval $(n=1)$ and bicaval $(n=2)$ cannulation. A right ventricular vent to drain the beating heart was used. Great care was taken to preserve the large azygos vein. Dissection of the mediastinum was minimal and surgical stapling was extensively used during removal of both lungs and opening of the mediastinum to avoid postoperative bleeding. The tracheobronchial bifurcation was approached through the aortocaval sinus, and all intertracheobronchial lymph nodes were resected and their vascular supply carefully secured. A passage between the right (behind the phrenic nerve) and left (behind the pulmonary veins) pleural and pericardial cavities was then created. ${ }^{10}$

Airway continuity was established by a separate, bilateral bronchial anastomosis ${ }^{11}$ in the aortocaval sinus starting with the right main stem bronchus. These patients have a long right bronchus and a shorter left main bronchus, and to keep this incongruity the right and left main bronchi of the recipient were transected approximately $1.5 \mathrm{~cm}$ from the carina (Fig. 2, $A$ ). The donor's right main stem bronchus was sectioned at its origin (Fig. 2, B) and anastomosed to the recipient's main stem bronchus with a continuous 4-0 polydioxanone (PDS, Ethicon, Inc., Somerville, N.J.) suture on the posterior membranous portion and interrupted 4-0 polydioxanone sutures on the cartilaginous portion. By contrast, the donor left main stem bronchus was transected proximal to its upper lobe takeoff and the anastomosis was done in an identical fashion (Fig. 2, B). The final lengths of the right and left main stem bronchi were thus approximately 4 and $2.5 \mathrm{~cm}$, respectively.

After completion of the bronchial anastomoses, the aorta was crossclamped and the heart arrested with a blood cardioplegic solution infused into the ascending aorta. Thereafter, the left
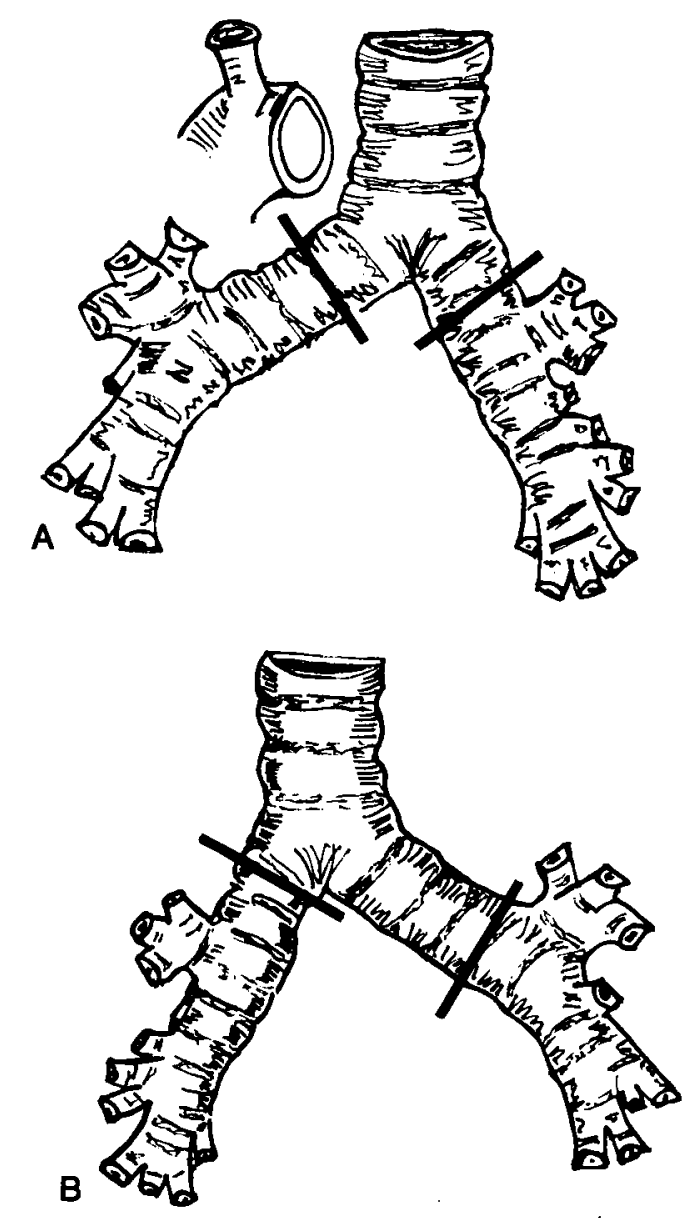

Fig. 2. En bloc DLT in patients with situs inversus and endstage Kartagener's syndrome. A, The long right and short left main bronchi of the recipient were divided approximately at $\mathbf{1 . 5}$ $\mathrm{cm}$ from the carina. B, Donor right main stem bronchus was sectioned at its origin and left main stem bronchus proximal to its upper lobe takeoff.

atrial and pulmonary artery anastomoses were made as described by Patterson and coworkers. ${ }^{7}$ Between the performance of the left atrial and pulmonary artery anastomoses, a line was introduced into the left atrium through its appendage to maintain a cool temperature and fill the left cardiac chambers. ${ }^{10}$ The pulmonary artery and left ventricle were deaired, the aorta declamped, and the heart defibrillated without spontaneous defibrillation.

Immunosuppression. Azathioprine $(2.5 \mathrm{mg} / \mathrm{kg}$ ) and methylprednisolone $(1 \mathrm{gm})$ were given intravenously immediately before graft perfusion. The induction immunosuppression regimen consisted of antilymphocyte globulin (5 days), intravenous cyclosporine (1 to $2 \mathrm{mg} / \mathrm{kg}$ per day), and azathioprine $(2.5$ $\mathrm{mg} / \mathrm{kg}$ per day). Corticosteroids were started on the fifth postoperative day. Maintenance immunosuppression was achieved by triple therapy; the dose adjustments of cyclosporine (6 to 10 $\mathrm{mg} / \mathrm{kg}$ per day) were made according to the whole blood levels of cyclosporine (200 to $300 \mathrm{ng} / \mathrm{ml}$ ). 
Transbronchial biopsies and bronchoalveolar lavages were systematically done on postoperative days 15,30, and 90 and each time abnormal signs and symptoms suggestive of rejection or infection occurred. Preventive cytomegalovirus hyperimmunoglobulin was given in patient $2(1 \mathrm{ml} / \mathrm{kg}$ daily $)$ from postoperative days 15 to 45 .

\section{Results}

All three patients received organs from $\mathrm{ABO}$, serology, and thoracic size compatible donors. The average lengths of donor and recipient operations were $65.6 \pm$ 9.01 and $385 \pm 56.7$ minutes, respectively. The mean lung ischemic time, duration of $\mathrm{CPB}$, and duration of cardioplegia were $207.6 \pm 76.7,198.6 \pm 20.7$, and $37 \pm 3.4$ minutes, respectively. The first two patients had their bronchial anastomoses performed as described earlier, but the last required a telescoping technique because the donor bronchus was larger than that of the recipient. The latter was also the only one who required a right lower lobectomy after implantation, because dextrocardia precluded expansion of the transplanted right lower lobe.

The postoperative course was uneventful for all three patients; none of them had postoperative hemodynamic pulmonary edema. Patient 1 was extubated on postoperative day 14 . This was the patient who required preoperative ventilatory support, had an incomplete early expansion of both lower lobes, and postoperatively had a bronchial suppuration with strains of methicillin-resistant Staphylococcus aureus. Patient 2 was extubated on postoperative day 1 and patient 3 on day 3. No early related bronchial anastomotic complication occurred except in patient 3 , who required placement of a metallic stent in the left main stem bronchus because of a stenosis.

During hospitalization, none of the patients showed signs of allograft rejection or cytomegalovirus infection. The patients were discharged 46,58 , and 60 days after the operation. At that time, they had recovered completely from their respiratory failure (Table II). Patient 1 is still alive 48 months after the operation and has returned to full-time employment (Fig. 3). Patient 2 did well during the first 12 months after transplantation; thereafter, he had several severe episodes of cytomegalovirus infections and subsequently graft rejections necessitating antirejection treatments, including total body irradiation. He ultimately died of severe obliterative bronchiolitis 36 months after the operation. Patient 3 is alive and well 6 months after the operation.

\section{Discussion}

The intrinsic defect of the respiratory cilia of patients with Kartagener's syndrome increases the propensity for recurrent or chronic infection at multiple sites along the respiratory tract. In young patients, this contributes to the
Table II. Respiratory function at the time of hospital discharge

\begin{tabular}{lccc}
\hline \multicolumn{1}{c}{ Respiratory function } & Patient 1 & Patient 2 & Patient 3 \\
\hline $\mathrm{FEV}_{1}, \mathrm{~L}$ (\% predicted value) & $1.37(55 \%)$ & $3(78 \%)$ & $1.38(44 \%)$ \\
$\mathrm{VC}, \mathrm{L}$ (\% predicted value) & $1.38(47 \%)$ & $3.2(70 \%)$ & $1.49(39 \%)$ \\
$\mathrm{FEV}_{1} / \mathrm{VC}$ (\% predicted & $99 \%$ & $94 \%$ & $119 \%$ \\
$\quad$ value) & & & \\
$\mathrm{PaO}_{2}(\mathrm{~mm} \mathrm{Hg})$ & 81 & 72 & 81 \\
$\mathrm{PaCO}_{2}(\mathrm{~mm} \mathrm{Hg})$ & 38 & 40 & 42 \\
\hline
\end{tabular}

$F E V_{l}$, Forced expiratory volume in the first second; $V C$, vital capacity; $\mathrm{PaO}_{2}$, arterial oxygen tension; $\mathrm{PaCO}_{2}$, arterial carbon dioxide tension.

development of bronchiectasis, bronchitis, and sinusitis ${ }^{12}$ and, ultimately, end-stage pulmonary failure. Lung transplantation might be an effective treatment modality for these patients, but its technical performance is anatomically limited by the presence of a situs inversus malformation. The primary considerations for selecting en bloc DLT and not heart-lung transplantation for our three patients were essentially dictated by (1) the necessity to optimize the limited pool of donor organs by avoiding the use of a heart and the related risks of early cardiac rejection and late coronary occlusive disease; (2) the absence of severe pulmonary hypertension; and (3) the significant technical challenge resulting from the restoration of a single atrium, as described by Miralles and associates. ${ }^{6}$

The two constants in patients with situs inversus are the complete reversal of the anatomic position of the heart chambers, pulmonary artery, aorta, and superior and inferior venae cavae and the inverse direction and length of the main stem bronchi and inverse position of both lungs. Among these abnormalities, dextrocardia does not represent a technical problem for the institution of cardiopulmonary bypass, but the systemic venous return must be maintained by preserving its unique venous collector, the large azygos vein. Otherwise, complex technical systemic venous reconstructions are necessary. ${ }^{13}$ The real difficulties in patients with situs inversus are the inverse direction and length of the main stem bronchi that obviously cannot be managed with the technique of en bloc DLT with tracheal anastomosis with ${ }^{14}$ or without ${ }^{7}$ airway revascularization.

We therefore decided to perform bilateral bronchial anastomoses in the aortocaval sinus and adapt the direction and length of the donor bronchi to the recipient's mediastinal anatomy. However, to minimize bronchial ischemia and thus airway complications, we were careful to leave the recipient's carina with its original vascularization because it is the milieu at higher risk of ischemia in en bloc DLT with tracheal anastomosis ${ }^{15}$ and to perform the bronchial bilateral anastomoses at an appropriate distance from the carina to facilitate the postoperative 


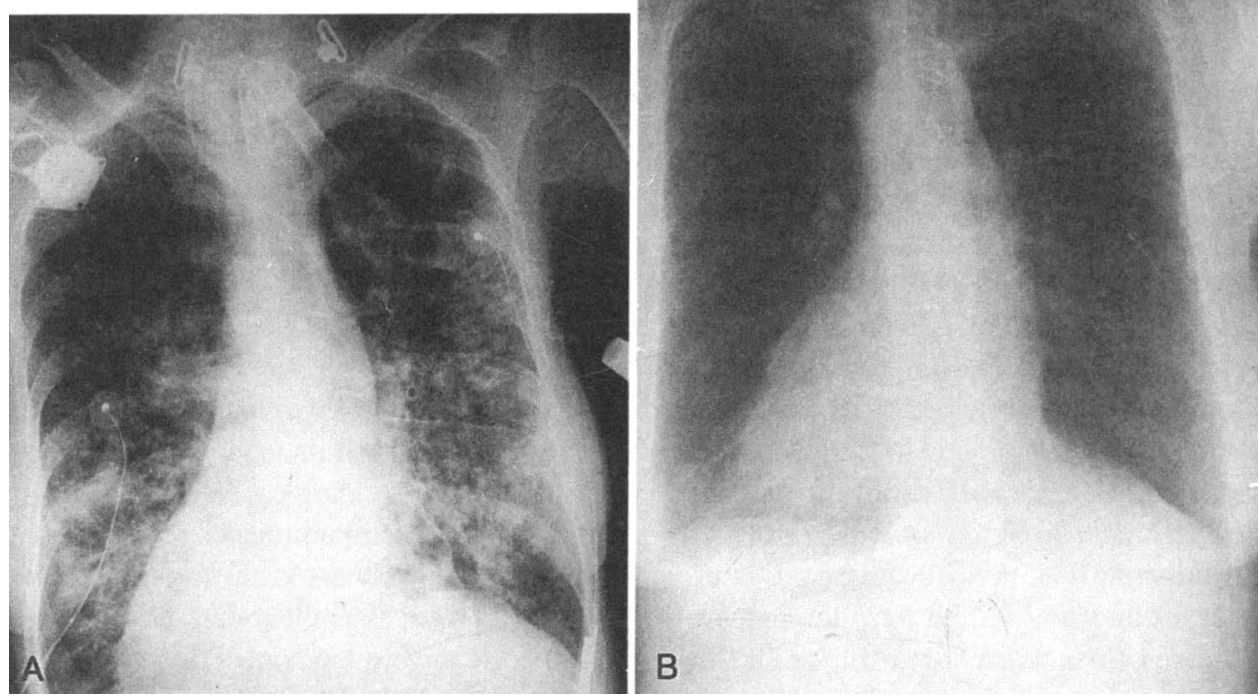

Fig. 3. A, Preoperative posteroanterior chest $x$-ray film of recipient 1 . The patient had a tracheostomy, a right central venous catheter whose tip clearly stops in the left-sided superior vena cava, dextrocardia, and multiple bilateral bronchiectasis located especially in the lower lobes. B, Chest x-ray film 48 months after en bloc DLT.

retrograde revascularization from bronchopulmonary collaterals. ${ }^{16}$ Moreover, a final length of the transplanted bronchi short enough to increase retrograde revascularization ${ }^{17}$ but long enough to avoid tension at the site of the anastomoses was desirable. To fill these imperatives, we transected the right and left main bronchi of the recipient approximately $1.5 \mathrm{~cm}$ from the carina. The right main stem bronchus of the donor was sectioned at its origin and the left main stem bronchus of the donor was divided proximal to its upper lobe takeoff. The different angulations of the two bronchi were not an obstacle, and these maneuvers restored the original lengths of the right and left main stem bronchi. Because the left atrium in patients with situs inversus is a midline structure that receives the left and right pulmonary veins and the pulmonary artery is a midline structure too, the anastomoses with the respective recipient structures were made as described by Patterson and colleagues. ${ }^{7}$

The described technique allowed successful en bloc DLT in three patients with Kartagener's syndrome and situs inversus. The only postoperative complication was observed in the last patient, whose left bronchial anastomosis was made with a telescoping technique. An early stenosis required the placement of a stent. This complication might have been the result of early airway ischemia at the airway anastomotic site or, to a lesser extent, to the telescoping technique in itself, because it is associated with a greater likelihood of airway complications than end-to-end anastomosis. ${ }^{18}$ After implantation, the expansion of the right lower lobe was inhibited by dextrocardia, for which a right lower lobectomy was done. Although one might argue that lobectomy could impair the recovery of pulmonary reserve, incomplete lower lobe expansion significantly impairs the already complicated postoperative course. Thus the surgeon should not hesitate to immediately perform a lobar resection. Lobectomy plus the fact that patients with Kartagener's syndrome and situs inversus have a deformity of the thoracic cage impose a perfect size-matching between the donor and recipient organs. Interestingly, the first patient was receiving ventilatory support and had a tracheostomy at the time of transplantation, but her respiratory impairment was not associated with increased morbidity after DLT, mirroring recent conclusions made by Massard and associates ${ }^{19}$ in patients with cystic fibrosis.

In conclusion, end-stage Kartagener's syndrome is an indication for lung transplantation, despite the presence of situs inversus. DLT with bilateral bronchial anastomoses in the aortocaval sinus appears to be the procedure of choice. Its advantages over heart-lung transplantation 
in terms of sparing a heart and avoiding surgical interventions on the recipient's atria are evident. Whereas the left atrial and pulmonary artery anastomoses are similar to those observed in patients with situs solitus, the inverse direction and length of the main stem bronchi are easily correctable and adaptable to the anatomy of the mediastinum with the presented technique. Dextrocardia might interfere with the expansion of the transplanted right lung, and the right lower lobe should be resected without hesitation. Our experience with bilateral sequential DLT ${ }^{20}$ is limited, because our procedure of choice for DLT has been the en bloc technique since the beginning of our transplant program. However, it appears to us that en bloc DLT has the advantage of technical simplicity about the vascular anastomoses over sequential DLT in patients with situs inversus and Kartagener's syndrome.

\section{Paris-Sud University Lung Transplant Group}

Surgery: P. Dartevelle, A. Chapelier, P. Vouhé, and P. Macchiarini

Pneumology: J. Cerrina, F. Le Roy Ladurie, P. Herve, F. Parquin, P. Duroux, F. Brenot, F. Parent, and G. Simonneau

Anesthesia: D. Lafont, D. Le Houerou, B. Barthelme, G. Remuzon, and F. Simoneau

Pathology: B. Rain and E. Dulmet

Psychiatry: C. Klein and F. Theodore

Infectiology: J.M. Liebert and P. Petitpretz

Immunology: S. Berrih-Aknin, M. Fattal, M. Humbert, and P. Galanaud

\section{REFERENCES}

1. Kartagener M. Zur Pathogenese der Bronchiectasien. Bietr Klin Tuberk 1933;83:489-501.

2. Rossman CM, Forrest JB, Ruffin RE, Newhouse MT. Immotile cilia syndrome in persons with and without Kartagener's syndrome. Am Rev Respir Dis 1980;121:1011-6.

3. Mayo P. Kartagener's syndrome. J THORAC CARdiovasC SURG 1960;42:39-42.

4. Reitz BA, Wallwork J, Hunt SA, et al. Heart-lung transplantation: successful therapy for patients with pulmonary vascular disease. N Engl J Med 1982;306:557-64.

5. Lung transplantation. Report of the ATS workshop on lung transplantation. Am Rev Respir Dis 1993;147:772-6.

6. Miralles A, Muneretto C, Gandjbakhch I, et al. Heart-lung transplantation in situs inversus. J THORAC CARDIOvaSC SuRG 1992;103:307-13.

7. Patterson GA, Cooper JD, Goldman B, et al. Technique of successful clinical double lung transplantation. Ann Thorac Surg 1988;4:626-33.

8. Sundarsen S, Trachiotis GD, Aoe M, Patterson GA, Cooper JD. Donor lung procurement: assessment and operative technique. Ann Thorac Surg 1993;56:1409-13.

9. Wallwork J. Preservation technique for heart-lung transplantation: In: Heart and heart-lung transplantation. Philadelphia: WB Saunders, 1989:1-521.

10. Vouhé PR, Dartevelle PG. Heart-lung transplantation: technical modifications that may improve the early outcome. J Thorac Cardiovasc Surg 1989;97:906-10.

11. Noirclerc MJ, Metras D, Vaillant A, et al. Bilateral bronchial anastomosis in double and heart-lung lung transplantations. Eur J Cardiothorac Surg 1990;4:314-7.

12. Reynolds HY. Normal and defective respiratory host defences. In: Pennington JE, ed. Respiratory infections: diagnosis and management. 2nd ed. New York: Raven Press, 1989:1-33.

13. Doty DB, Renlund DG, Caputo GR, Burton NA, Jones KW. Cardiac transplantation in situs inversus. J THORAC Cardiovasc Surg 1990;99:493-9.

14. Couraud L, Baudet E, Martigne C, et al. Bronchial revascularization in double lung transplantation. Ann Thorac Surg 1992;53:88-94.

15. Patterson AG, Todd TR, Cooper JD. Airway complications after double lung transplantation. J THORAC CARDIOvASC SURG 1990;99:14-21.

16. Pearson FG, Goldberg M, Stone RM, Colapinto RF. Bronchial arterial circulation restored after reimplantation of canine lung. Can J Surg 1970;13:243-50.

17. Pinsker KL, Koerner SK, Kamholz SL, Hagstrom JWC, Veith FJ. Effect of donor bronchial length on healing: a canine model to evaluate bronchial anastomotic problems in lung transplantation. J Thorac Cardovasc Surg 1979;77:669-73.

18. Grimm M, Wisser W, End A, et al. Early experience with sequential bilateral lung transplantation. J THORAC CARDIOvASC SURG 1993;106:463-5.

19. Massard G, Shennib H, Metras D, et al. Double-lung transplantation in mechanically ventilated patients with cystic fibrosis. Ann Thorac Surg 1993;55:1087-92.

20. Kaiser LR, Pasque MK, Trulock EP, Low DE, Dresler $\mathrm{CM}$, Cooper JD. Bilateral sequential lung transplantation: the procedure of choice for double-lung transplantation. Ann Thorac Surg 1991;52:438-46. 